\title{
Best of the Best Articles of 2020
}

\author{
Mahesh Kumar Goenka ${ }^{1}$ Shivaraj Afzalpurkar ${ }^{1}$ \\ ${ }^{1}$ Institute of Gastrosciences and Liver, Apollo Gleneagles Hospitals, \\ Kolkata, India
}

J Digest Endosc 2021;12:1-2.

Year 2020 gave a unique experience to each and every individual of our society. It taught us some of the unknown and unfamiliar concepts such as "social distancing," "lockdowns," "virtual meetings," "mask mandates," and "second wave." We learned to adapt to the risk of unknown unknowns. Our journal made a good beginning last year by dedicating its first issue to articles related to COVID issues, particularly in respect of gastrointestinal endoscopy. It gave some clear concepts on COVID-19 and endoscopy practice that helped the practicing gastroenterologists and especially endoscopists to face the challenge of COVID-19 pandemic in a better way. I sincerely appreciate all the authors of the March 2020 issue for putting their efforts in making the issue fruitful. It covered all the aspects of COVID-19, including epidemiology and infectivity to treatment. We are happy to announce the articles that we consider "best" published in the Journal of Digestive Endoscopy in 2020.

\section{Best Original Articles}

An article, "Outcomes of double balloon enteroscopy for managing overt small bowel bleeding," by Dalal et al ${ }^{1}$ highlighted the role of double-balloon enteroscopy in the diagnosis and treatment of small bowel pathological conditions and how it reduces the need for immediate surgical interventions.

The second article, "Endoscopic management of postlaparoscopic sleeve gastrectomy leaks: a single-center experience," by Jagtap et $\mathrm{al}^{2}$ enlightened us how post-laparoscopic sleeve gastrectomy leaks can be managed by endotherapy with significant success rates and acceptable morbidity. They also showed how improvement in stent designs along with supplementary use of other endoscopic therapeutic modalities can further improve clinical success in such patients.

Another good article was "Use of n-butyl 2 cyanoacrylate without lipiodol, using a modified protocol in gastric variceal bleed management: retrospective analysis of 2299 patients" by Desai et al. ${ }^{3}$ The authors showed how endoscopic

\begin{abstract}
Address for correspondence Mahesh Kumar Goenka, Department of Gastroenterology Apollo Gleneagles Hospitals, Day care building, 4th floor Kankurgachi, Kolkata 700054, West Bengal India (e-mail: gastrojournal_aghl@apollohospitals.com).
\end{abstract}

ultrasound (EUS)-guided angiotherapy is an effective and safe intervention for managing gastric variceal bleeding with high technical success rate.

A nationwide survey of Indian gastroenterologists on "perception and practices of colonoscopy procedure" by Jha and $\mathrm{Babu}^{4}$ assessed the practices and policies of performing colonoscopy by gastroenterologists in our region. It highlighted their preferences in conducting colonoscopies that will help formulate practice guideline for a successful and safe colonoscopy.

Jagtap et $\mathrm{al}^{5}$ studied the clinical impact of universal screening for COVID-19 before therapeutic endoscopy. There is a scarcity of literature to support such screening prior to therapeutic endoscopy. Since the second wave of COVID-19 seems to be knocking at our door, it will definitely guide the practicing endoscopists to formulate a screening protocol based on their local needs and resource availability.

Lastly, in this category, another good article was "Endoscopic treatment of upper gastrointestinal bleeding using Haemoseal Spray: a retrospective, observational study from a tertiary center in north India" by Bansal et al. ${ }^{6}$ In this study, it was found that Haemoseal Spray was an effective and safe tool in the endoscopic management of upper gastrointestinal bleed due to diffuse or multiple focal lesions as well as focal lesions refractory to conventional endotherapy.

\section{Best Review Articles}

When the first issue of our journal was published in March 2020, there was hardly any literature on impact of COVID-19 on gastrointestinal symptoms and endoscopy practice. Three best articles of that issue were "2019 novel coronavirus infection: gastrointestinal manifestations" by Samanta et al, "Risk of COVID-19 transmission during gastrointestinal endoscopy" by Rana, ${ }^{8}$ and "Indications for gastrointestinal endoscopy during the COVID-19 pandemic" by Gunjan and Garg. ${ }^{9}$ Other best review articles published in the
DOI https://doi.org/ 10.1055/s-0041-1729138 ISSN 0976-5042
(C)2021. Society of Gastrointestinal Endoscopy of India.

This is an open access article published by Thieme under the terms of the Creative Commons Attribution-NonDerivative-NonCommercial-License, permitting copying and reproduction so long as the original work is given appropriate credit. Contents may not be used for commercial purposes, or adapted, remixed, transformed or built upon. (https://creativecommons.org/licenses/by-nc-nd/4.0/).

Thieme Medical and Scientific Publishers Pvt. Ltd. A-12, 2nd Floor, Sector 2, Noida-201301 UP, India 
Journal of Digestive Endoscopy in 2020 were "Interpretation of benign gastric mucosal lesions using narrow-band imaging" by Paghadhar et $\mathrm{al}^{10}$ and "EUS-guided celiac plexus interventions" by Sharma et al. ${ }^{11}$

\section{Best Articles in Other Categories}

A case report by Kothakota et al, ${ }^{12}$ on small bowel angiodysplasia managed with novel motorized spiral enteroscope, demonstrated multiple angiodysplasia lesions in ileum that were managed with argon plasma coagulation during motorized spiral enteroscopy-a new kid on the block in the field of small bowel enteroscopy. Another case report by Balekuduru et al, ${ }^{13}$ "Endoscopic ultrasound-guided transgastric fine needle aspiration of splenic metastasis," reported how EUS-guided fine needle aspiration is a useful modality for cytopathological diagnosis of splenic lesions. We also had an interesting case series "Common bile duct polyp-rare but not so rare cause of obstructive jaundice" by Kabrawala et al. ${ }^{14}$ They described clinical presentation and histopathological characteristics of five patients with common bile duct polyps. In the Videos section, Singh et al $^{15}$ demonstrated endoscopic management of obstructive jaundice in pregnancy due to hepatic hydatid disease. Another interesting endoscopic video by Zimmer showed eosinophilic esophagitis stricture dilatation using BougieCap using ancillary rotational movements under both endoscopic and haptic control. ${ }^{16}$

Overall, the editorial board is satisfied with the progress of the quality of the journal. Of course, we expect and invite review articles, original articles, and interesting videos from our endoscopy fraternity. Wishing you a successful and healthy 2021.

\section{Conflict of Interest}

None declared.

\section{References}

1 Dalal A, Patil G, Maydeo A. Outcomes of double balloon enteroscopy for managing overt small bowel bleeding. J Dig Endosc 2020;11(2):118-125
2 Jagtap N, Yashavanth HS, Kalapala R, et al. Endoscopic management of postlaparoscopic sleeve gastrectomy leaks: a single-center experience. J Dig Endosc 2020;11(2):134-137

3 Desai PN, Patel CN, Kabrawala MV, et al. Use of n-butyl 2 cyanoacrylate without lipiodol, using a modified protocol in gastric variceal bleed management: retrospective analysis of 2299 patients. J Dig Endosc 2020;11(3):187-192

4 Jha JM, Babu S. Perception and practices of colonoscopy procedure: a nationwide survey of Indian gastroenterologists. J Dig Endosc 2020;11(4):253-257

5 Jagtap N, Singh AP, Inavolu P, Tandan M, Lakhtakia S, Reddy DN. Clinical impact of universal screening for COVID-19 before therapeutic endoscopy. J Dig Endosc 2020;11(4):270-274

6 Bansal RK, Gupta MK, Gupta VK, Kaur G, Seth AK. Endoscopic treatment of upper gastrointestinal bleeding using Haemoseal Spray: a retrospective, observational study from a tertiary center in North India. J Dig Endosc 2020;11(4):279-282

7 Samanta J, Dhar J, Khaliq A, Kochhar R. 2019 novel coronavirus infection: gastrointestinal manifestations. J Dig Endosc 2020;11(1):13-18

8 Rana SS. Risk of COVID-19 transmission during gastrointestinal endoscopy. J Dig Endosc 2020;11(1):27-30

9 Gunjan D, Garg P. Indications for gastrointestinal endoscopy during the COVID-19 pandemic. J Dig Endosc 2020;11(1):33-38

10 Paghadhar S, Jain M, Mahadevan B, Venkataraman J. Interpretation of benign gastric mucosal lesions using narrow-band imaging. J Dig Endosc 2020;11(2):106-111

11 Sharma ZD, Bansal RK, Puri R. EUS-guided celiac plexus interventions. J Dig Endosc 2020;11(3):177-181

12 Kothakota SR, Sasidharan M, Kareem H, Nair AK. Small bowel angiodysplasia managed with novel motorized spiral enteroscope: a case report. J Dig Endosc 2020;11(2):156-168

13 Balekuduru AB, Kapali AS, Kurella SP, Subbaraj SB. Endoscopic ultrasound-guided transgastric fine needle aspiration of splenic metastasis. J Dig Endosc 2020;11(3):238-241

14 Kabrawala M, Desai P, Mehta R, et al. Common bile duct polyp-rare but not so rare cause of obstructive jaundice. J Dig Endosc 2020;11(4):283-286

15 Singh AP, Asif S, Lakhtakia S, Reddy DN. Endoscopic management of obstructive jaundice in pregnancy due to hepatic hydatid disease. J Dig Endosc 2020;11(4):295-296

16 Zimmer V. BougieCap dilation in eosinophilic esophagitis for stricture treatment under visual and haptic control. J Dig Endosc 2020;11(3):223-224 